\title{
MINERAÇÃO EM SERRAS TOMBADAS
}

MINING IN HERITAGE LISTED HILLS

\author{
${ }^{1}$ José Adércio Leite Sampaio \\ ${ }^{2}$ Thiago Loures Machado Moura Monteiro
}

\section{RESUMO}

O presente trabalho tem como objetivo analisar a possibilidade de tombamento que impeça a atividade minerária já exercida na área tombada. São considerados os interesses econômicos do minerador, amparados pela segurança jurídica, livre iniciativa e pelo direito de propriedade, em conflito com o interesse coletivo e jusfundamental de proteção do patrimônio cultural. Defende-se uma interpretação pro natura e pro cultura que não esvazie os direitos do minerador, mas que faça valer adequadamente a proteção constitucionalmente exigida àquele patrimônio. A metodologia de pesquisa utilizada é a bibliográfica, de cunho qualitativo, aliada à jurisprudência e o estudo de caso.

Palavras-chave: Direito transgeracional, Tombamento, Mineração, Patrimônio cultural

\begin{abstract}
This study aims to analyze the possibility of occurrence of public heritage listing that prevents mining activities already exercised in that area. They are considered the economic interests of mining, supported by legal certainty, free enterprise and the right to property, in conflict with the collective and constitutional interest in cultural heritage protection. It defends an interpretation pro natura and pro cultura that does not exhaust the rights of mining, but which upholds the constitutional protection of cultural rights. The methodology used is the literature of qualitative, coupled with the jurisprudence and the cases study.
\end{abstract}

Keywords: Transgenerational righs, Heritage register, Mining, Cultural heritage

\footnotetext{
1 Doutor em Direito pela Universidade Federal de Minas Gerais. Pocurador da República do Ministerio Publico Federal. Universidade Federal de Minas Gerais - UFMG, Minas Gerais. Brasil

E-mail: joseadercio@terra.com.br

2 Mestrando em Direito Ambiental pela Escola Superior Dom Helder Câmara. Escola Superior Dom Helder

Câmara - ESDHC, Minas Gerais. Brasil

E-mail: thiagoloures.adv@gmail.com
} 


\section{INTRODUÇÃO}

A discussão sobre a atividade minerária voltou a tomar conta dos noticiários, pelo maior desastre ambiental brasileiro, ocorrido na cidade de Mariana, no rompimento de uma barragem de rejeitos de mineração, que vitimou, pelo menos, dezenove pessoas, destruiu vilas e comprometeu seriamente o equilibrio do meio ambiente, incluindo a morte de um dos principais rios do Brasil, o Doce.

A exploração mineral é fonte de recursos importantes para o Brasil e é responsável por um grande número de empregos diretos e indiretos (REIS; SILVA, 2015). Todavia, é uma das atividades mais invasivas ao meio ambiente e mesmo ao patrimônio histórico e cultural (FARIAS, 2002).

A Constituição brasileira dedica-se, como poucas, à prescrição de um direito ao meio ambiente ecologicamente equilibrado, associado a tarefas estatais e comunitárias de sua defesa. Também reconhece os direitos culturais, dentre os quais, o patrimônio cultural brasileiro, impondo ao Poder Público e à coletividade o dever de preservá-lo. Entre os dois, existe a solda do pacto intergeracional (SAMPAIO, 2003).

É sabido que um dos instrumentos de proteção do patrimônio cultural mais usuais é o tombamento. Como o decreto do tombamento prevê, de regra, a proibição da mineração na área tombada, é de se perquirir a legitimidade constitucional dessa proibição em vista do direito à propriedade privada, da segurança jurídica e da livre iniciativa.

Por meio de revisão bibliográfica e jurisprudencial, bem como de estudo de casos, procura-se responder a essa indagação. Na elaboração discursiva do trabalho, analisa-se o patrimônio cultural como elemento da função socioambiental da propriedade privada, destacando-se o tombamento como instrumento de sua proteção. Segue-se com um exame da exploração minerária como aspecto da livre iniciativa e do instituto da propriedade, trazendo à discussão o debate sobre o tema que é central ao texto: a vedação da atividade minerária em decorrência de tombamento superveniente.

\section{PATRIMÔNIO CULTURAL COMO ELEMENTO DA FUNÇÃO SOCIOAMBIENTAL DA PROPRIEDADE PRIVADA}

$\mathrm{O}$ constitucionalismo trouxe $\mathrm{o}$ direito à propriedade para o centro dos direitos fundamentais, ao lado da vida, liberdade e segurança (NEDELSKY, 1994). Sua compleição 
normativa era praticamente irresistível a intervenções estatais, ressalvadas as hipóteses, na prática, de difícil ocorrência, de desapropriação para interesse público. Essa visão quase absolutista da propriedade deu lugar a uma concepção funcionalizada: a legitimação da propriedade exigia o cumprimento por seu titular de uma função social, hoje dita, alargadamente, socioambiental (SAMPAIO, 2013).

A propriedade, como dispõe o artigo 1.228 do Código Civil brasileiro, atribui ao titular o direito de dela usar, dispor e gozar, podendo reivindicá-la de quem injustamente a possua ou detenha (BRASIL, 2002).

Os direitos a que o artigo se refere como inerentes da propriedade privada (usar, dispor, gozar), devem ser exercidos, porém, em cumprimento à sua função socioambiental, também por mandamento normativo.

A Constituição Federal de 1988 já previra a função social como elemento estrutural do direito fundamental no seu artigo $5^{\circ}$ inciso XXIII; e ainda a sua função ecológica, prevista no art. 225, $\S 1^{\circ}$, inciso VII e no art. 186, inciso II (BRASIL, 1988). O Código Civil o fez de modo também expresso no art. $1.228, \S 1^{\circ}$ :

\begin{abstract}
$\S 1^{\circ} \mathrm{O}$ direito de propriedade deve ser exercido em consonância comas suas finalidades econômicas e sociais e de modo que sejam preservados, de conformidade com o estabelecido em lei especial, a flora, a fauna, as belezas naturais, o equilíbrio ecológico e o patrimônio histórico e artístico, bem como evitada a poluição do ar e das águas. (BRASIL, 2002, s/p)
\end{abstract}

Sobre a função socioambiental, Daniela Oliveira Gonçalves e Élcio Nacur Rezende apontam os três aspectos básicos da função socioambiental da propriedade:

Dos estudos realizados, pode-se concluir que a função socioambiental atualmente se apresenta basicamente sob três aspectos: econômico (produtividade), social (bemestar dos proprietários e trabalhadores e direitos trabalhistas) e ambiental (utilização adequada dos recursos naturais e preservação do meio ambiente). Não basta que a propriedade seja produtiva. Ela também deve cumprir os demais requisitos impostos pela lei, sob pena de desapropriação para fins de reforma agrária. (GONÇALVES; REZENDE, 2014, p. 152)

O sentido de função socioambiental, como elemento interno (imanente ou diretamente constitucional) ou externo à propriedade, de qualquer modo, dela condicionador, é ligado ao de patrimônio cultural. A Constituição, de modo expresso, reconhece os direitos culturais de todos, cabendo ao Estado apoiar e incentivar a valorização e a difusão das manifestações culturais (art. 215). 
Assim também considera patrimônio cultural brasileiro os bens de natureza material e imaterial, tomados individualmente ou em conjunto, portadores de referência à identidade, à ação, à memória dos diferentes grupos formadores da sociedade brasileira, inclusivamente os conjuntos urbanos e sítios de valor histórico, paisagístico, artístico, arqueológico, paleontológico, ecológico e científico, devendo o Poder Público, com a colaboração da comunidade, promover e proteger o patrimônio cultural brasileiro, por meio de inventários, registros, vigilância, tombamento e desapropriação, e de outras formas de acautelamento e preservação (art. 216, caput, V e $\S 1^{\circ}$ ) (BRASIL, 1988).

Ressaltando que conforme preceitua a Constituição, o dever de zelar pelo meio ambiente equilibrado, para presentes e futuras gerações, não é apenas de uma parcela da sociedade, mas sim de toda a coletividade, incluindo o empreendedor, que tem como objetivo básico a obtenção de lucro, mas não pode se desvincular de sua responsabilidade ambiental.

Sendo que a concepção da função socioambiental, foi construída por meio de um processo lento e gradativo, resultado da mudança de paradigmas socioculturais, desde o paradigma liberal, passando pelo socialista, até concretizar no paradigma do Estado Democrático de Direito, que contempla a função socioambiental (PINTO, 2015).

A propriedade pode sofrer condicionamentos quando incide sobre bem ou objeto que componha o patrimônio cultural brasileiro, máxime - mas não apenas - quando já acautelado por um dos instrumentos constitucionalmente previstos, nos quais se inclui o tombamento.

E especificamente sobre o papel do tombamento, na proteção do patrimônio cultural, ressaltando a função socioambiental da propriedade, no próximo item será abordado desde a origem da expressão "tombamento", até a sua previsão legal atual.

\section{O PAPEL DO TOMBAMENTO NA PROTEÇÃO DO PATRIMÔNIO CULTURAL}

A expressão 'tombamento' tem origem em Portugal, quando o rei D. Fernando, no ano de 1378, utilizou a torre conhecida como torre do tombo, para ser o arquivo real, de documentos e objetos que deveriam ser preservados, pela sua importância para a Coroa (MIRANDA, 2014). O legislador brasileiro optou por utilizar a expressão advinda da cultura portuguesa, no Decreto-lei 25/1937, que regula atualmente o instituto do tombamento (BRASIL, 1937).

O entendimento majoritário, inclusive jurisprudencial, é que a Constituição de 1988 recepcionou o Decreto-Lei $25 / 1937$, a teor do que dispõe o seu art .216 , $\S 1^{\circ}$, e $\S 5^{\circ}$ (BRASIL, 
1988).

No $\S 1^{\circ}$ do art. 216, a Constituição reconhece o tombamento como um dos meios de promover e proteger o patrimônio cultural brasileiro. O $\S 5^{\circ}$ declara tombados os documentos e sítios detentores de reminiscências históricas dos antigos quilombos. Como a Constituição não indica que uma nova lei deverá regular o instituto presume-se que ela reconhece a validade da regulamentação já existente.

A recepção do Decreto-Lei 25/1937 é reconhecida pela jurisprudência, de que é exemplo o seguinte julgado:

TOMBAMENTO. DECRETO-LEI 25/37. RECEPÇÃO PELA ATUAL CONSTITUIÇÃO (ART. 216). CONJUNTO ARQUITETÔNICO TOMBADO. REFORMA DE IMÓVEL DELE INTEGRANTE. 1. O Decreto-Lei 25/37 foi recepcionado pela atual Constituição, a qual, no parágrafo $1^{\circ}$ do artigo 216 , é expressa ao estabelecer que a proteção ao patrimônio cultural brasileiro far-se-á "por meio de inventários, registros, vigilância, tombamento e desapropriação, e de outras formas de acautelamento e preservação". 2. Estando comprovado que o imóvel tombado em causa foi objeto de modificação, sem autorização da autoridade administrativa competente, restou violado o comando previsto no artigo 17 do Decreto-Lei 25, de 30.11.1937. 3. A ausência do embargo da obra não obsta à incidência da necessidade de prévia autorização. Precedente desta Corte. 4. A ausência de averbação não constitui fundamento jurídico suficiente para afastar a obrigatoriedade da autorização administrativa para a realização de reforma no imóvel tombado, ou seja, a eficácia da limitação administrativa. Precedente desta Corte. 5. Apelação e remessa, tida por interposta, não providas. (BRASIL, 2002) ${ }^{1}$.

\footnotetext{
${ }^{1}$ De se vê que as cortes mais têm reconhecido a recepção implicitamente com a discussão relativa a seus aspectos processuais e requisitos. Vejam-se, dentre vários, no STF: RE 602930 AgR, Rel. Min. Rosa Weber, Primeira Turma (BRASIL, 2014). No STJ: REsp 41.993/SP, Rel. Min. Milton Luiz Pereira, Primeira Turma; REsp 840918 / DF. Rel. Min. Herman Benjamin, Segunda Turma (BRASIL, 1995 e 2008).
} 
É preciso notar, todavia, que o caput do art. 216 ampliou o conceito de patrimônio cultural brasileiro, para além do toque de excepcionalidade como o caracterizara para fins de tombamento, o referido Decreto-Lei. Agora, compõem-no, como ditos, os bens de natureza material e imaterial, tomados individualmente ou em conjunto, portadores de referência à identidade, à ação, à memória dos diferentes grupos formadores da sociedade brasileira, nos quais se incluem: as formas de expressão; os modos de criar, fazer e viver; as criações científicas, artísticas e tecnológicas; as obras, objetos, documentos, edificações e demais espaços destinados às manifestações artístico-culturais; e os conjuntos urbanos e sítios de valor histórico, paisagístico, artístico, arqueológico, paleontológico, ecológico e científico (BRASIL, 1988).

A recepção do Decreto-Lei 25/1937 deve ser interpretada considerando a ampliação constitucional do conceito de patrimônio cultural brasileiro, bem como o dever de proteção ambiental, como direitos constitucionais coexistentes. Nesse sentido, Vicente de Paulo Augusto de Oliveira Júnior, assim dispôs:

Com a promulgação da Constituição Federal de 1988, o conceito de patrimônio cultural e também o de bem cultural foram ampliados, permitindo novas possibilidades de proteção. E, diferentemente de alguns doutrinadores que acreditamser a revogação do Decreto-lei $n^{\circ}$ 25/1937 a solução para problemas e lacunas existentes na proteção ao patrimônio cultural, entende-se que este foi, em sua substância, recepcionado, e seus conceitos devidamente complementados e ampliados. (OLIVEIRA JÚNIOR, 2014, p. 247)

Logo, a recepção do instituto do tombamento, permite concluir que ele deve ser utilizado como instrumento de proteção do patrimônio cultural, no caso da presente pesquisa, em serras de relevância cultural. E tal proteção se encaixa na esfera dos direitos transgeracionais, ou seja, não apenas a geração presente possui o direito de ter determinada serra preservada, por sua importância cultural, mas também as gerações que estão por vir, as chamadas gerações futuras, são detentoras do direito de preservação e de contemplação das serras tombadas, por serem patrimônio cultural.

E tal raciocínio sobre o direito transgeracional, é decorrente da redação literal do caput do artigo 225 da Constituição Federal, que assim dispõe:

Art. 225. Todos têm direito ao meio ambiente ecologicamente equilibrado, bem de uso comum do povo e essencial à qualidade de vida, impondo-se ao Poder Público e à 
coletividade o dever de defendê-lo e preservá-lo para as presentes e futuras gerações. (BRASIL, 1988, s/p)

Contudo, mesmo tendo em vista este dever em relação as gerações futuras o aspecto econômico tem de ser levado em consideração, para uma análise sistêmica do objeto da pesquisa, por isso será tratado no próximo item, sobre a exploração minerária como elemento da livre inciativa e propriedade privada, sem desconsiderar o aspecto preservacionista $\mathrm{e}$ transgeracional, do direito ambiental.

\section{A EXPLORAÇÃO MINERÁRIA COMO ELEMENTO DA LIVRE INICIATIVA E PROPRIEDADE PRIVADA}

A atividade minerária é historicamente uma das grandes fontes de riqueza do Brasil. Em verdade, muitas das utilidades e comodidades hoje existentes, a passarem pelos smartphones e aparelhos médicos de última geração, dependem do ingresso, na cadeia produtiva, dos minérios extraídos do solo e do subsolo brasileiros (REIS; SILVA, 2015).

Ressaltando que a Constituição federal inclusive contempla expressamente o direito à livre iniciativa e a propriedade privada, que em uma visão neoconstitucional, onde se busca dar efetividade ao texto constitucional, ganham roupagem especial em um debate jurídico (OLIVEIRA, 2013).

A Constituição federal também atribui à União a propriedade sobre os recursos minerais, podendo autorizar a pesquisa e conceder a lavra de tais recursos, no interesse nacional, a brasileiros ou empresa constituída sob as leis brasileiras e que tenha sua sede e administração no País (BRASIL, 1988, art. 20, IX; 176, § $1^{\circ}$ ). Uma vez concedida a lavra, o seu titular passa a deter o direito de explorá-lo de acordo com os termos de concessão.

Entretanto tal direito de exploração não pode ser compreendido como um direito absoluto, mas sim um direito que tem o dever de cumprir sua função socioambiental, em relação a área a ser explorada, e seus impactos, inclusive no prisma cultural.

A titularidade do título de concessão minerária gera, para além de direitos, deveres como o de explorar dentro de certo prazo e o de respeitar o meio ambiente. Para tanto, faz inversões, muitas das vezes, expressivas na espera do retorno adequado. Se parece menos problemático que não possa o Estado permitir que se explore recurso mineral em área previamente tombada (MACHADO, 2010), a inquietação é grande quando se trata de tombamento superveniente que interfira com a exploração minerária existente. Há, nesse caso, 
um direito à exploração associado a uma expectativa de retorno econômico-financeiro, amparado no direito de propriedade, na segurança jurídica e na livre iniciativa, todos garantidos constitucionalmente. Que haverá de prevalecer?

Para avançar no estudo à procura da resposta, abordar-se-ão casos concretos em que o assunto se impôs, seguindo-se do exame das correntes que procuram enfrentá-lo.

\section{ESTUDOS DE CASOS}

Alguns casos concretos mostram a atualidade e importância da questão. Trata-se de serras tombadas para fins de proteção cultural e ambiental, em que já eram exercidas atividades minerárias, designadamente a Serra do Curral e a Serra da Piedade.

\subsection{Caso da Serra do Curral}

A mineração na Serra do Curral, compreendida entre os municípios de Belo Horizonte e Nova Lima, iniciou em 1973, perdurando, por quase três décadas, até o ano de 2002, quando se encerrou o ciclo produtivo. Os efeitos danosos da mineração perduram até o presente. Apesar da imponente faixada, a Serra é hoje um enorme vão, atualmente enchido de água. Os danos são tão evidentes que, passados mais de 10 anos do fim das atividades minerárias, a parte degradada ainda não pode ser aberta para visitação.

Em 07.01.2004, a Prefeitura de Belo Horizonte publicou, no diário oficial, a deliberação $n^{\circ}$ 147/2003, da Secretaria Municipal de Coordenação de Política Urbana e Ambiental, tornando definitivo o tombamento da Serra do Curral (BELO HORIZONTE, 2004).

Na referida deliberação, ficou estabelecido que não fosse mais dada autorização para pesquisa ou lavra mineral, e ainda que fossem implantadas medidas de recuperação das áreas afetadas (BELO HORIZONTE, 2004).

A questão do tombamento não afetou mais diretamente o direito de exploração em curso, todavia suscitou uma polêmica de cunho federativo importante: Pode o Município, por meio do tombamento, proibir a autorização para pesquisa ou lavra mineral? Há quem refute essa possibilidade em nome de uma prevalência federal de competência. (FREIRE, 2005, p. 
174). O exercício do direito da União em conceder a lavra, todavia, não se pode sobrepor à competência municipal de preservar o patrimônio cultural, que é um dever de todos os entes federativos e da sociedade, convolando-se numa questão de ordem pública (MACHADO, 2010).

No dia 16.05.2014, foi iniciado o projeto de recuperação em razão da mineração, com previsão de término da obra para 2017, como explicado em reportagem do Estado de Minas:

\footnotetext{
O lado da Serra do Curral que os moradores de Belo Horizonte e visitantes nunca veem e que foi degradado por décadas de mineração vai ganhar proteção com telas de aço, como se fossem quadros afixados a uma parede, e cobertura vegetal para dar um aspecto natural à montanha escavada para retirada de minério. Para recuperar essa área importante do maciço que foi eleito pela população símbolo maior da capital, tombado pelo Instituto do Patrimônio Histórico e Artístico Nacional (IP), serão usados helicópteros para transportar o material até o topo da montanha, emárea de 90 mil metros quadrados. Também entrarão em ação profissionais es pecializados, os alpinistas industriais, para atuar ao lado de 160 operários. A movimentação no município vizinho de Nova Lima, na região metropolitana, começa hoje, adianta a direção da empresa Vale, responsávelpelo serviço previsto para terminar em 2017. (Site http://www.em.com.br, 2014)
}

Fato é que até o momento não existe previsão de quando tal parte da Serra do Curral será novamente aberta à visitação, sendo que as futuras gerações tiveram perda do direito de contemplação da Serra, enquanto patrimônio cultural preservado.

\subsection{Caso da Serra da Piedade}

A serra da Piedade, compreendida entre os municípios de Caeté e Sabará, em Minas Gerais, tem a marca inicial da mineração, ainda na época da colonização portuguesa.

No dia 16.06.2004, o Estado de Minas Gerais realizou o tombamento da Serra da Piedade, por meio da Lei n. 15.178/2004 (MINAS GERAIS, 2004), proibindo, no mesmo ato, a atividade minerária. Diferentemente do ocorrido na Serra do Curral, não tinha havido ainda o encerramento do ciclo produtivo das minas da Serra da Piedade.

A partir de então, iniciou-se uma serie de discussões sobre a legalidade e o alcance do tombamento feito pelo Estado de Minas Gerais, e se ele tinha o efeito de impedir a atividade das mineradoras na região.

Em 2005, o Ministério Público Federal ajuizou ação civil pública, a fim de paralisar as atividades da mineradora Brumafer, que até então realizava atividade minerária na região. 
Como argumento central, o MPF alega que a Serra da Piedade, na época, já contava com três tombamentos e duas áreas de conservação. É fato. Além do tombamento estadual já indicado, há existia tombamento municipal, previsto na Lei Orgânica do Município de Caeté/MG, no art. 202, e tombamento federal, pelo IPHAN, Livro do Tombo Histórico.

O tombamento federal, porém, dava margem à discussão, pois incidia apenas sobre a arquidiocese do topo da serra. Seus limites foram ampliados muito recentemente, em agosto de 2015, e passou a contemplar a preservação do grande conjunto cênico e paisagístico serrano, que liga Caeté e Sabará. O tombamento municipal e o estadual poderiam padecer de vícios competenciais como vistos (FREIRE, 2005). O direito material houve de prevalecer sobre o princípio da hierarquia - inexistente - entre as unidades federativas.

Na ação civil pública, foi deferida liminar e atualmente a mineração na região está suspensa.

Após a explanação sobre os estudos de caso, resta verificado que a inexistência de um tombamento durante o ciclo produtivo da serra do curral, gerou dano irreparável as futuras gerações, ante a degradação ambiental produzida. Lado outro, os argumentos sob desenvolvimento e progresso, para derrubar a proibição da atividade minerária na serra da piedade, pelo seu tombamento, não foram capazes de liberar a atividade, ante ao caráter protetivo preservacionista do direito ambiental, enquanto um direito transgeracional. No próximo item será abordado de forma específica, sobre os principais debates jurídicos em torno do tema.

\section{A POLÊMICA DO TOMBAMENTO EM ÁREAS COM EXPLORAÇÃO MINERÁRIA}

Já se apresentou o problema central do artigo: a possibilidade de tombamento superveniente impedir a exploração existente em área minerária. A doutrina diverge a respeito.

William Freire está do lado dos que defendem a possibilidade de manter as atividades minerárias mesmo com o tombamento. O ponto de partida do referido autor é justamente a ideia da coerência do ordenamento jurídico. A proteção do patrimônio cultural pode e deve, em regra, ser considerada num contexto de coexistência harmônica com o desenvolvimento econômico, como se verifica em lição do aludido autor: 
Os mecanismos de proteção ao ambiente não são, de forma alguma, impeditivos ao exercício da atividade produtiva. Ao contrário, dentro de uma visão moderna e inteligente da Administração Pública, orientada para o cumprimento de suas funções conforme os preceitos insculpidos no art. 37 da Constituição Federal (legalidade, impessoalidade, moralidade, publicidade, eficiência), o Estado é o primeiro interessado no progresso socioeconômico. Dentro dessa perspectiva, os órgãos ambientais são estimulados a criar mecanismos de orientação e licenciamentos das atividades econômicas. (FREIRE, 2005, p. 158)

Dessa forma, segundo o aludido autor, será possível promover o princípio do desenvolvimento sustentável, sem criar empecilhos deliberados ou desnecessários ao progresso econômico (FREIRE, 2005, p.158). A se admitir a vedação superveniente, haveria um esvaziamento do direito de propriedade. Para tanto, seria necessária prévia e justa indenização em dinheiro:

O desapossamento do Requerimento de Pesquisa com Certificação de Prioridade, do Alvará de Pesquisa ou da Portaria de Lavra deve ser precedido de justa indenização em dinheiro, equivalente ao valor da parte do patrimônio do expropriado que for diminuída. (FREIRE, 2005, p. 175)

Cabe aqui ponderar, que de fato, em uma análise superficial, não há empecilho da proteção ao meio ambiente, ser simultâneo ao desenvolvimento econômico. Desde que tal desenvolvimento econômico não represente riscos e danos intoleráveis nem comprometa a disponibilidade cultural e ambiental das futuras gerações (BECHARA, 2009).

Para Guilherme José Purvin de Figueiredo, condicionar a aplicação da preservação, ao pagamento de indenização prévia, é retirar eficácia da norma geral de proteção ao patrimônio cultural brasileiro (FIGUEIREDO, 2010). José Eduardo Ramos Rodrigues corrobora o entendimento, sob alegação da impossibilidade de o Estado não ter condições financeiras para arcar com os custos de uma indenização prévia ao tombamento para a proteção ao patrimônio cultural (RODRIGUES, 1993). Ou é demonstrado que há um bem de valor cultural importante a ser preservado, incidindo sobre as propriedades em que se localiza limitações diretas e imediatas, sem necessidade de indenização; ou se estará descumprindo o dever jusfundamental de proteção ao patrimônio cultural:

\footnotetext{
Nosso país é pobre e continuará a sê-lo por longo tempo. Nem por is so os brasileiros constituem-se num povo inferior sem direito de fruição de seu patrimônio cultural, transmissível às futuras gerações, como qualquer país civilizado do mundo. Até porque uma das formas de superação do subdesenvolvimento mais eficazes implica na valorização por um povo de seus bens culturais, através dos quais consegue afirmarse realmente como nação. A indenização ou expropriação de bens culturais por nossos débeis cofres públicos afasta para sempre qualquer possibilidade de preservação do patrimônio cultural brasileiro. (RODRIGUES, 1993, p. 200)
} 
Ao se falar em preservação do patrimônio cultural, deve-se reconhecer sua natureza transgeracional, por fazer parte da tutela difusa e integrante, ao menos parcialmente, do sistema de proteção do meio ambiente ecologicamente equilibrado.

Ramos explica como deve se portar o juiz na aplicação da tutela especifica ambiental:

Este juiz deve ser antes de tudo um cidadão livre, e não um escravo da lei como postulavam os juristas de Napoleão. Quer dizer, não deve ser um escravo do projeto monoteísta que só conhece uma solução única para os problemas plurais da sociedade complexa e contemporânea. O juiz intergeracional é alguém capaz de abrir a própria mente e reconstruir a racionalidade do conhecimento jurídico que adquiriu nos tempos de sua formação universitária. (RAMOS, 2014, p. 307).

Para o aludido autor, até mesmo conceitos processuais como coisa julgada, irretroatividade das leis, segurança jurídica, e previsibilidade do direito, considerados basilares do devido processo legal, devem ser relativizados em razão da tutela ambiental, conceitos (RAMOS, 2014).

O tombamento deve ser visto como um instrumento para efetivar tal tutela. Paulo Affonso Leme Machado defende a importância de se dar ampla validade às limitações impostas em um tombamento, não permitindo a atividade minerária em área tombada:

\begin{abstract}
As florestas ou outras formas de vegetação e o solo que integrem um sítio tombado não poderão, portanto, ser destruídos pela exploração de recursos minerais, ainda que se proponha uma futura recuperação. O sítio privado ou público que for tombado merece a integral proteção naquilo que eles contém atualmente, que não pode ser modificado antropocentricamente, a não ser para cuidados de manutenção. (MACHADO, 2010, p. 717).
\end{abstract}

Marcos Paulo de Souza Miranda também defende a abstenção da atividade de mineração em área tombada:

Assim, não se admite, por exemplo, exploração de recursos minerais em uma serra objeto de proteção por tombamento, pois, nos termos do art. 17 do DL n. 25/1937, é juridicamente vedado qualquer ato que implique em mutilar ou destruir a coisa tombada e as atividades minerárias são tipicamente degradantes e destrutivas. (MIRANDA, 2014, p.98).

É certo que o desenvolvimento econômico deve existir na sociedade, tendo inclusive previsão constitucional no art. 170; contudo, no mesmo artigo, indica-se que deve ser observada a proteção ao meio ambiente. Logo, a mineração em área tombada, por colocar em risco concreto a preservação do patrimônio cultural preservado, deve ser restringida ou, em caso de 
impossibilidade de coexistência, proibida, ainda que supervenientemente, sem gerar direito à indenização prévia.

O que pode é o minerador, em momento subsequente, postular seu eventual direito junto à União. Esse eventual direito não pode ir além do que foi efetivamente investido e de real e demonstrada perda de oportunidade negocial, mas sempre ex tunc e nunca profuturo. Parece a forma adequada de equacionar o conflito existente entre o interesse econômico e o de proteção jusfundamental do patrimônio cultural.

Dessa forma, eventual indenização seria por valores efetivamente gastos pelo empreendedor, e não pode ser arbitrada sobre projeções de lucro futuro. Mas independente do alcance da indenização, fato é que a mesma não representa óbice para a proibição de se minerar uma determinada serra tombada, sob pena de negar prestação jurisdicional a uma ameaça de lesão para presentes e futuras gerações.

\section{CONSIDERAÇÕES FINAIS}

A propriedade privada deve cumprir, mais do que seu vocacionado papel de utilidade econômica, a função socioambiental que engloba o dever jusfundamental de proteção do patrimônio cultural.

Por patrimônio cultural brasileiro, compreende-se não apenas os termos do DecretoLei 25/1937, que foi recepcionado pela Constituição de 1988, mas também, em sua noção mais ampla, prevista no caput do art. 216 da Constituição, os bens de natureza material e imaterial, tomados individualmente ou em conjunto, portadores de referência à identidade, à ação, à memória dos diferentes grupos formadores da sociedade brasileira, nos quais se incluem: as formas de expressão; os modos de criar, fazer e viver; as criações científicas, artísticas e tecnológicas; as obras, objetos, documentos, edificações e demais espaços destinados às manifestações artístico-culturais; e os conjuntos urbanos e sítios de valor histórico, paisagístico, artístico, arqueológico, paleontológico, ecológico e científico.

E em razão da coexistência harmônica de direitos, surge o dever de coerência do ordenamento jurídico, ao interpretar e aplicá-los, máxime quando ocorre um aparente conflito entre eles. É o caso presente entre propriedade e área tombada, designadamente quando ocorre um tombamento em área de exploração minerária, com a determinação superveniente de cessação da atividade. 
Por meio dos exemplos práticos em Minas Gerais, da Serra do Curral e da Serra da Piedade, demonstrou-se que a questão vai além da especulação teórica, apresentando-se como um tema prático e presente no cotidiano brasileiro, a exigir uma reflexão mais profunda.

As peculiaridades da proteção cultural, como aspecto consorciado à proteção ambiental, induzem uma interpretação mais generosa pro cultura como pro natura, nos casos de conflitos com outros interesses constitucionais, sobretudo de índole econômica e patrimonial.

Ante tal tutela diferenciada, mostra-se inviável a coexistência harmônica das atividades minerárias, em um bem tombado, haja vista a impossibilidade de compensação, e o dever de reparação integral, que se aplica ao patrimônio cultural brasileiro.

Não se pode exigir, portanto, na superveniência de um tombamento impeditivo de atividade minerária já exercida na área tombada que ocorra a prévia indenização. Nada impede, todavia, que o minerador possa buscar o ressarcimento do que fora por ele investido no empreendimento minerário e até postular a indenização pela real e demonstrada perda de oportunidade negocial, de modo ex tunc e nunca profuturo.

\section{REFERÊNCIAS}

BECHARA, Érica. Licenciamento e Compensação Ambiental na Lei do Sistema Nacional das Unidades de Conservação. São Paulo: Atlas, 2009.

BELO HORIZONTE. Deliberação municipal no 147/2003, de 07 de janeiro de 2004. Torna definitivo o tombamento da Serra do Curral, em Belo Horizonte. Diário Oficial do Município de Belo Horizonte, Belo Horizonte, 07 jan. 2004.

BRASIL. Constituição da República Federativa do Brasil, de 1988. Diário Oficial da União, Brasilia, 5 out. 1988.

BRASIL. Decreto-lei 25, de 30 de novembro de 1937. Organiza a proteção do patrimônio histórico e artístico nacional. Diário Oficial da União, Rio de Janeiro, 6 dez. 1937.

BRASIL. Lei $\mathrm{n}^{\mathrm{a}}$ 10.406, de 10 de janeiro de 2002. Instituiu o Código Civil. Diário Oficial da União, Brasilia, 11 jan. 2002.

BRASIL. Supremo Tribunal Federal. Processo: 361127 SP. Rel. Min. Joaquim Barbosa. Diário de Justiça, 01 de ago. de 2012.

BRASIL. Supremo Tribunal Federal. 1 ${ }^{\text {a }}$ Turma. RE 602930 AgR, Rel. Min. Rosa Weber, julgado em 11/03/2014. Disponível em: <http://redir.stf.jus.br/paginadorpub/paginador.jsp? docTP=TP\&docID=5512470>. Acesso em 15/03/2016. 
BRASIL. Superior Tribunal de Justiça. $1^{\text {a }}$ Turma. REsp 41.993/SP, Rel. Min. Milton Luiz Pereira, julgado em 01/06/1995. Disponível em: < https://ww2.stj.jus.br/processo/ita/listarAcordaos? classe $=\&$ num_processo $=\&$ num_registro $=199300354833 \& d t \_$publicacao=19/06/1995 > . Acesso em 15/03/2016.

BRASIL. Superior Tribunal de Justiça. 2a Turma. REsp 840.918/DF. Rel. p/ acórdão Min. Herman Benjamin, julgado em 14/10/2008, Disponível em $<$ https://ww2.stj.jus.br/processo/revista/inteiroteor/? num_registro=200600860111\&dt_publicacao=10/09/2010>. Acesso em 15/03/2016.

BRASIL. Tribunal Regional Federal da $1^{a}$ Região. Processo: 1998.01.00.093579-2 MT. Rel. Juiz Convidado Leão Aparecido Alves. Diário de Justiça, 05 de set. de 2002.

CAETÉ. Lei orgânica do município de Caeté, promulgada em 14 de agosto de 1990. Dentre outras medidas estabelece o tombamento do conjunto cultural arquitetônico, paisagístico e natural da Serra da Piedade a partir da cota de 1.200 metros até o cume, dentro dos limites do município - Governo Federal (IPHAN). Diário Oficial do Município de Caeté, Caeté, 14 ago. 1990 .

COELHO, Helena Carvalho. Do Direito Constitucional ao meio ambiente e desdobramentos principio ló gicos à hermenêutica (ambiental?). Revista Veredas do Direito- Direito Ambiental e Desenvolvimento Sustentável. Belo Horizonte: Arraes Editores, v. 11, n.21, p.53-73, jan./jun. 2014.

FARIAS, Carlos Eugênio G. Mineração e meio ambiente no Brasil. Relatório do CGEE/PNUD, 2002. Disponível em: <

http·/www.em.ufop.br/ceamb/petamb/cariboost_files/miner_c3_a7_c3_a3o_20e_20meio_20a mbiente.pdf $>$. Acesso em 15/03/2016.

FIGUEIREDO, Guilherme José Purvin de. A propriedade no direito ambiental. São Paulo: Revista dos Tribunais, 2010.

FREIRE, William. Direito Ambiental aplicado à mineração. Belo Horizonte: Mineira, 2005.

GONÇALVES, Daniela Oliveira; REZENDE, Élcio Nacur. Função socioambiental da propriedade: A busca por uma determinação pragmática de aferição de cumprimento. Revista Direito e Justiça - Reflexões Sociojurídicas - Ano XIII - No 22, p. 133-154-Abril 2014.

JORNAL ESTADO DE MINAS. Telas de aço vão remendar a Serra do Curral. [2014]. Disponível em: <http://www.em.com.br/app/noticia/gerais/2014/05/16/interna_gerais,529385/telas-de-acovao-remendar-a-serra-do-curral.shtml . Acesso em 18 out. 2015.

MACHADO, Paulo Affonso Leme. Direito ambiental brasileiro. São Paulo: Malheiros, 2010.

MINAS GERAIS. Lei estadual $n^{\circ} 15.178$, de 16 de junho de 2004. Define os limites de conservação da serra da Piedade, conforme o art. $84, \S 1^{\circ}$, do Ato das Disposições 
Constitucionais Transitórias da Constituição do Estado. Diário Oficial do Estado de Minas Gerais, Belo Horizonte, 16 jun. 2004.

NEDELSKY, Jennifer. Private property and the limits of American constitutionalism: The Madisonian framework and its legacy. Chicago: University of Chicago Press, 1994.

OLIVEIRA JÚNIOR, Vicente de Paulo Augusto de Oliveira; A participação da comunidade na proteção ao patrimônio cultural: uma análise do decreto-lei $n^{\circ}$ 25/1937 à luz da constituição federal de 1988. Revista Veredas do Direito- Direito Ambiental e Desenvolvimento Sustentável. Belo Horizonte: Arraes Editores, v. 11, n.21, p.215-253, jan./jun. 2014.

PINTO, João Batista Moreira. Os direitos humanos como um projeto de sociedade. In: PINTO, João Batista Moreira; SOUZA, Eron Geraldo de (Organizadores). Os direitos humanos como um projeto de sociedade: desafios para dimensões política, socioeconômica, ética, cultural, jurídica e socioambiental. Rio de Janeiro: Lumen Juris, 2015. Cap.1, p. 5-34.

RAMOS, Dempsey. O Futuro como fundamento gnoseológico de validade do direito ambiental. Revista Veredas do Direito- Direito Ambiental e Desenvolvimento Sustentável. Belo Horizonte: Arraes Editores, v. 11, n.21, p.281-315, jan./jun. 2014.

REIS, Julio Cesar; SILVA, Harley. Mineração e desenvolvimento em Minas Gerais na década 2000-2010. Novos Cademos NAEA, v. 18, n. 3, 2015.

RODRIGUES, José Eduardo Ramos. Tombamento e patrimônio cultural. In: BENJAMIN, Antônio Herman V. (coord.). Dano ambiental: prevenção, reparação e repressão. São Paulo: Revista dos Tribunais, 1993, Cap. III, p. 180- 225.

SAMPAIO, José Adércio L.. A Constitucionalização dos Princípios de Direito Ambiental. In: SAMPAIO, J. Adércio L.; WOLD, Cris; NARDY, Afrânio (Org.). Princípios de direito ambiental- na dimensão internacional e comparada. Belo Horizonte: Del Rey, 2003, Cap. II, p. 45-85.

SAMPAIO, José Adércio L. Teoria da Constituição e dos Direitos Fundamentais. Belo Horizonte: Del Rey, 2013.

OLIVEIRA, Márcio Luís. A Constituição juridicamente adequada. Belo Horizonte: Arraes Editores, 2013. 